\title{
Multiple causes of death related to Chagas' disease in Brazil, 1999 to 2007
}

\author{
Francisco Rogerlândio Martins-Melo ${ }^{[1],[2]}$, Alberto Novaes Ramos Junior ${ }^{[1]}$, \\ Carlos Henrique Alencar ${ }^{[1],[2]}$ and Jorg Heukelbach ${ }^{[1],[3]}$
}

[1]. Departamento de Saúde Comunitária, Faculdade de Medicina, Universidade Federal do Ceará, Fortaleza, CE. [2]. Swiss Tropical and Public Health Institute, University of Basel, Basel, Switzerland. 3. School of Public Health, Tropical Medicine and Rehabilitation Sciences, James Cook University, Townsville, Australia.

\section{ABSTRACT}

Introduction: Chagas' disease is a major public health problem in Brazil and needs extensive and reliable information to support consistent prevention and control actions. This study describes the most common causes of death associated with deaths related to Chagas' disease (underlying or associated cause of death). Methods: Mortality data were obtained from the Mortality Information System of the Ministry of Health (approximately 9 million deaths). We analyzed all deaths that occurred in Brazil between 1999 and 2007, where Chagas' disease was mentioned on the death certificate as underlying or associated cause (multiple causes of death). Results: There was a total of 53,930 deaths related to Chagas' disease, 44,543 (82.6\%) as underlying cause and 9,387 (17.4\%) as associated cause. The main diseases and conditions associated with death by Chagas' disease as underlying cause included direct complications of cardiac involvement, such as conduction disorders/arrhythmias (41.4\%) and heart failure (37.7\%). Cerebrovascular disease (13.2\%), ischemic heart disease (13.2\%) and hypertensive diseases $(9.3 \%)$ were the main underlying causes of deaths in which Chagas' disease was identified as an associated cause. Conclusions: Cardiovascular diseases were often associated with deaths related to Chagas' disease. Information from multiple causes of death recorded on death certificates allows reconstruction of the natural history of Chagas' disease and suggests preventive and therapeutic potential measures more adequate and specifics.

Keywords: Chagas' disease. Mortality. Underlying cause of death. Multiple causes of death. Epidemiology. Brazil.

\section{INTRODUCTION}

The World Health Organization (WHO) recommends mortality statistics to be presented by the underlying cause of death. This is defined as the disease or injury, which initiated the cascade of events leading directly to death, or the circumstances of accident or violence that produced fatal injury ${ }^{1}$. However, especially for infectious and parasitic diseases, there is a need for more comprehensive information on fatal events. Additionally, there is a clear relevance to consider all causes of death recorded on death certificates. These include in addition to the underlying causes of death the associated causes that increase the risk of complications, and other contributing causes not directly related to the process that led to death. These three groups together are called multiple causes of death ${ }^{2,3}$.

In Brazil, with significant reduction of vector and blood-borne transmission, the number of cases of acute form of Chagas' disease has been drastically reduced in most endemic areas ${ }^{4}$. In addition, both increased knowledge about the natural history of disease and better effectiveness of clinical and surgical interventions, led to the reduction of specific mortality and increased survival of infected individuals ${ }^{5}$. Recent estimates amount to 2 to 3 million individuals infected with the causing agent Trypanosoma cruzi in Brazil ${ }^{6-8}$. A large proportion of these cases occurred in old persons, which increases particularly the risk of

Address to: Dr. Jorg Heukelbach. Depto de Saúde Comunitária/FM/UFCE. Rua Professor Costa Mendes 1608, Bloco Didático/5o andar, 60430-140 Fortaleza, CE, Brasil.

Phone: 5585 3366-8045

e-mail: heukelbach@web.de

Received in 14/05/2012

Accepted in 03/09/2012 association non-infectious chronic diseases such as cardiovascular diseases and neoplasms 9 .

Given this new scenario of morbidity and mortality caused by Chagas' disease and the association with other chronic diseases, it is reasonable to expect that a higher number of causes of death directly or indirectly related to this disease will be observed in the next decades ${ }^{10}$.

The present nationwide study aimed to describe contributing causes of death associated with death due to Chagas' disease.

\section{METHODS}

\section{Study design and population}

We performed a nationwide population-based study using secondary mortality data. We included all deaths in Brazil during the period 1999 to 2007, where Chagas' disease was recorded in any part of the medical certificate of cause of death (underlying or associated cause of death). The underlying cause of death is defined the disease or injury that initiated the train of morbid events and that led directly to death ${ }^{1}$, and multiple causes as the set of all causes listed on death certificates without distinct classification (basic, consequential or contributing) ${ }^{11}$.

Chagas' disease as a cause of death was defined in the presence of any clinical forms included in the category B57 (Chagas' disease) of the tenth revision of the International Statistical Classification of Diseases and Related Health Problems (ICD-10) ${ }^{1}$.

\section{Data Source}

We obtained data from the Mortality Information System (Sistema de Informações sobre Mortalidade - SIM) of the Brazilian 
Ministry of Health. Sistema de Informações sobre Mortalidade data are public domain and can be obtained from the website of the Statistical Department of the Unified Health System (Departamento de Informática do Sistema Único de Saúde - DATASUS) ${ }^{12}$. Sistema de Informações sobre Mortalidade data sets are based on the death certificates (Declaração de óbito), which consist of standardized forms to be filled out by the physicians in charge ${ }^{13}$. The death certificates contain demographic and clinical information regarding the underlying and multiple causes of death.

We included only deaths from 1999 and later, as a new version of SIM was launched that year, based on a new death certificate form ${ }^{13}$. In this new form, a line was added in part I (line d) upon the recommendation of the World Health Organization, to enable the declaration of a larger number of diagnoses and of associated causes of death ${ }^{14}$.

\section{Data processing and analysis}

Data processing has been described in detail previously ${ }^{10}$. Briefly, we downloaded and processed all 243 mortality data sets from the study period, with about 9 million entries. Field codes from different data sets were standardized. We then selected all death certificates with Chagas' disease in any line of the certificate as cause of death (both underlying and associated causes). As in many death certificates more than one cause was noted per line, we created new variables for different causes of death.

Duplication of death events was eliminated by identifying and counting causes in the database. Only one cause was included (category or grouping of ICD-10) if two (or more) causes belonging to this class were recorded in the same death certificate ${ }^{2}$.

In order to reconstruct the disease process that possibly led to death related to Chagas' disease, all causes reported on the death certificate were analyzed, even ill-defined and those characterized by WHO as modes of death, such as cardiorespiratory arrest and multiple organ failure ${ }^{1,3}$.

Data were stored and analyzed using STATA version 11 (Stata Corporation, College Station, USA).

\section{Ethical considerations}

The information on deaths related to Chagas' disease were obtained from computerized databases of the SIM as provided on the website of the DATASUS. This information is public domain and has no variables related to the identification of individuals. Thus, it was not necessary to submit the project to an institutional Ethics Review Board.

\section{RESULTS}

In Brazil, from 1999 to 2007, there were 53,930 deaths in which Chagas' disease was mentioned as a cause of death, 44,543 (82.6\%) as the underlying cause and $9,387(17.4 \%)$ as an associated cause of death. During the observation period, the mean mortality rate increased by $21.4 \%$ ( 2.8 vs. 3.4 deaths per 100,000 inhabitants), while the increase of mean proportional mortality was $20 \%$ (0.5\% vs. $0.6 \%$ ). Chagas' disease, as the underlying cause, was the fourth leading cause of death (10.8\%) of all infectious and parasitic diseases in the period.

Among the underlying causes of death due to Chagas' disease, 37,800 (84.9\%) were due to chronic cardiac forms, and 4,208 (9.4\%) due to chronic digestive forms. In 1,097 (2.5\%) cases, acute cardiac involvement was mentioned, in 1,157 (2.6\%) chronic involvement of other organs, and in $281(0.6 \%)$ other clinical forms of the disease (involvement of the nervous system and acute form without cardiac involvement).

The associated causes of death in those with Chagas' disease as the underlying cause are presented in Table 1. There was a clear predominance of conditions occurring during the natural history of Chagas' disease, specifically diseases of the circulatory, respiratory and digestive systems. Direct complications of cardiac involvement, especially conduction disorders/arrhythmias and heart failure, were mentioned in more than $35 \%$ of deaths, followed by shock (15\%) (Table 1). The mean number of mentions of heart conditions or causes in deaths due to Chagas' disease as the underlying cause was 1.00 $(44,643 / 44,543)$ per death certificate, while the mean mentions for circulatory diseases (Chapter IX - ICD-10) was 1.17 (52,212/44,543).

Interestingly, there was a considerable number of deaths due to complications related to medical treatment and surgical procedures (T80-T88 and Y83-Y84), affecting 4\% of total deaths due to Chagas' disease (Table 1).

Regarding contributory causes, there was a predominance of causes of death related to chronic diseases of the circulatory system, namely hypertensive diseases, ischemic heart and cerebrovascular disease (Table 1).

Table 2 details underlying causes of death for deaths in which Chagas' disease was mentioned as an associated cause. Here the pattern is slightly different. The most common underlying causes were diseases of the circulatory and respiratory systems which reached $59 \%$ of deaths in which Chagas' disease was associated cause, followed by neoplasms and digestive diseases, with $11.6 \%$ and $10.6 \%$ of deaths, respectively (Table 2). Cerebrovascular diseases, ischemic heart disease and hypertensive diseases were the main underlying causes of death, when Chagas' disease was identified as an associated cause. Chronic pulmonary diseases, particularly chronic obstructive pulmonary disease were also an important cause of death (Table 2). Despite the predominance of causes related to the chronic cardiovascular and pulmonary complex, acute infectious diseases such as septicemia and pneumonia also played an important role as the underlying cause, accounting for $10.1 \%$ deaths (Table 2 ).

\section{DISCUSSION}

The present study shows that information from multiple causes of death recorded on death certificates allowed partial reconstruction of the natural history and the reconstitution of the morbid process of determining death by Chagas' disease ${ }^{3}$. Given the fact that multiple causes and conditions often lead to death of an individual, the use of merely the underlying cause of disease is not be sufficient to describe the real epidemiological situation of a chronic condition such as Chagas' disease. In addition, the use of multiple causes of death allows identification of conditions that may be synergistic to death and opens new perspectives for the prevention and treatment of these comorbidities².

We observed that the main conditions associated with death by Chagas' disease have been inserted into the group of diseases of the 
TABLE 1 - Associated causes of death in those patients with Chagas disease as underlying cause, 1999-2007 (multiple mentions possible, Chagas' disease as associated cause excluded).

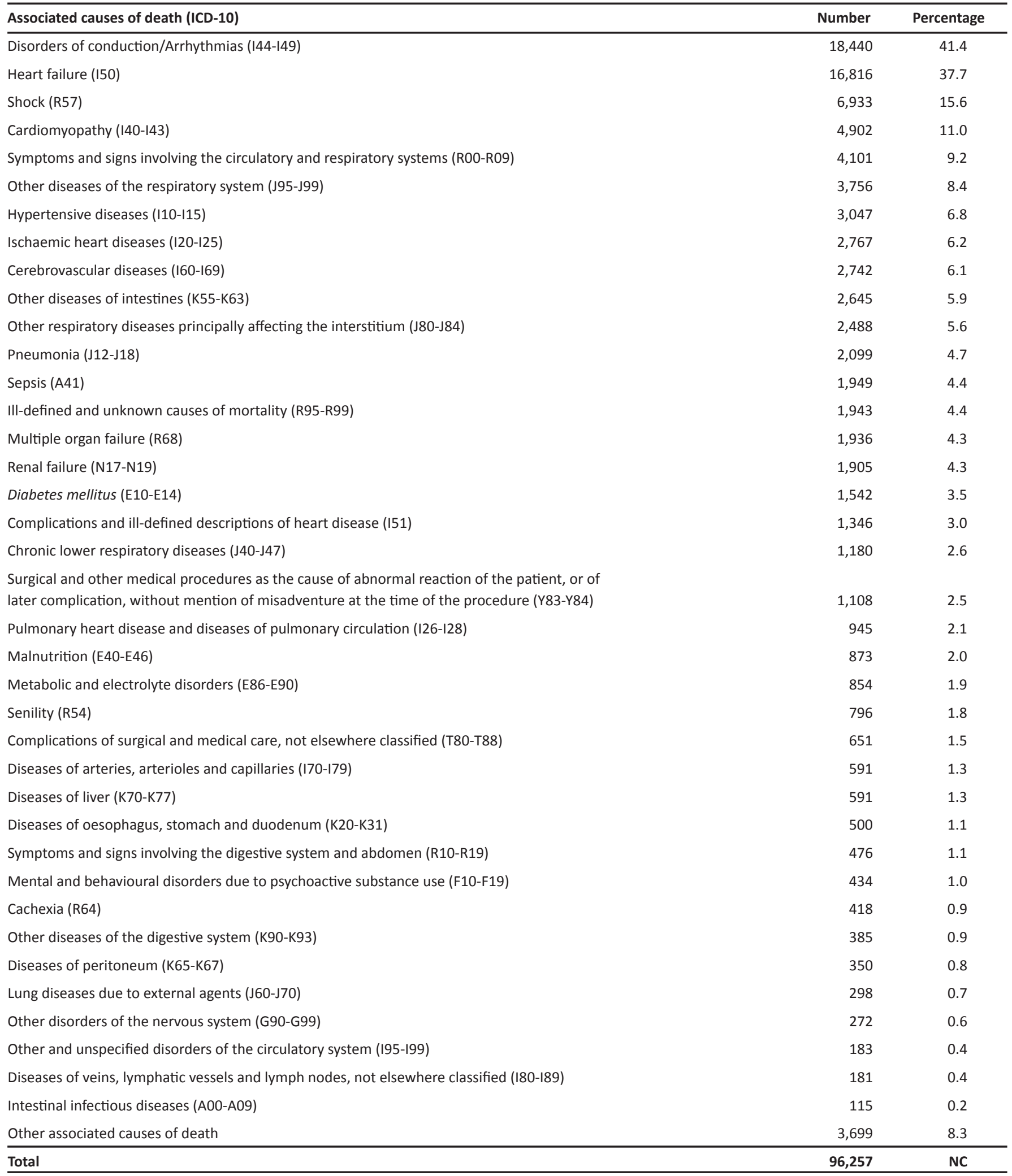

NC: not calculated. 
TABLE 2 - Underlying causes of death on death certificates with Chagas disease as an associated cause, Brazil, from 1999 to 2007.

\begin{tabular}{|c|c|c|}
\hline Underlying causes of death (ICD-10) & Number & Percentage \\
\hline Cerebrovascular diseases (I60-169) & 1,243 & 13.2 \\
\hline Ischaemic heart diseases (I20-I25) & 1,236 & 13.2 \\
\hline Hypertensive diseases (I10-I15) & 868 & 9.3 \\
\hline Chronic lower respiratory diseases (J40-J47) & 563 & 6.0 \\
\hline Pneumonia (J12-J18) & 532 & 5.7 \\
\hline Sepsis (A40-A41) & 414 & 4.4 \\
\hline Other diseases of intestines (K55-K63) & 398 & 4.2 \\
\hline Diabetes mellitus (E10-E14) & 365 & 3.9 \\
\hline Diseases of arteries, arterioles and capillaries (170-179) & 171 & 1.8 \\
\hline Malignant neoplasm of esophagus (C15) & 165 & 1.8 \\
\hline Diseases of liver (K70-K77) & 157 & 1.7 \\
\hline Disorders of gallbladder, biliary tract and pancreas (K80-K87) & 146 & 1.6 \\
\hline Other diseases of the respiratory system (J95-J99) & 144 & 1.5 \\
\hline Pulmonary heart disease and diseases of pulmonary circulation (I26-128) & 127 & 1.3 \\
\hline Cardiomyopathy (142-143) & 115 & 1.2 \\
\hline Diseases of esophagus, stomach and duodenum (K20-K31) & 113 & 1.2 \\
\hline Malignant neoplasm of stomach (C16) & 102 & 1.1 \\
\hline Malignant neoplasm of bronchus and lung (C34) & 102 & 1.1 \\
\hline Malignant neoplasms of ill-defined, secondary and unspecified sites (C76-C80) & 98 & 1.0 \\
\hline Malnutrition (E40-E46) & 92 & 1.0 \\
\hline Malignant neoplasm of prostate (C61) & 88 & 0.9 \\
\hline Renal failure (N17-N19) & 81 & 0.9 \\
\hline Other diseases of urinary system (N30-N39) & 69 & 0.7 \\
\hline Lung diseases due to external agents (J60-J70) & 66 & 0.7 \\
\hline Diseases of peritoneum (K65-K67) & 63 & 0.7 \\
\hline Intestinal infectious diseases (A00-A09) & 62 & 0.7 \\
\hline Malignant neoplasm of colon (C18) & 59 & 0.6 \\
\hline Tuberculosis/sequelae of tuberculosis (A15-A19, B90) & 58 & 0.6 \\
\hline Human immunodeficiency virus (HIV) disease (B20-B24) & 57 & 0.6 \\
\hline Other diseases of the digestive system (K90-K93) & 55 & 0.6 \\
\hline Sequelae of other and unspecified infectious and parasitic diseases (B94) & 55 & 0.6 \\
\hline Complications and ill-defined descriptions of heart disease (I51) & 51 & 0.5 \\
\hline Diseases of veins, lymphatic vessels and lymph nodes, not elsewhere classified (I80-I89) & 51 & 0.5 \\
\hline Falls (W00-W19) & 44 & 0.5 \\
\hline Complications of medical and surgical care (Y40-Y84) & 44 & 0.5 \\
\hline Other underlying causes of death & 1,333 & 14.2 \\
\hline Total & 9,387 & 100.0 \\
\hline
\end{tabular}

circulatory system, corroborating previous studies ${ }^{3,15}$. Consistent with the clinical descriptions and the predominance of chronic chagasic cardiopathy (CCC) as the main cause of death, cardiac complications were the main associated diseases, particularly arrhythmias/ conduction disorders, heart failure and cardiomyopathies. The frequent presence of other associated causes considered terminal, such as shock, pneumonia and sepsis reflects the severity of the process related to Chagas' disease ${ }^{3}$. The importance of hypertensive disease and ischemic heart disease as contributing causes was also evident, similarly to cerebrovascular diseases. This association with Chagas' disease has concerned some investigators previsouly ${ }^{16-20}$.

The identification of underlying causes responsible for the deaths in which Chagas' disease is presented as associated cause increases knowledge also on the association of causes related to mortality due to Chagas' disease. Due to the increased survival among patients with Chagas' disease in recent decades ${ }^{5}$, there was a greater likelihood of accumulation of chronic diseases such as diabetes, atherosclerosis, obesity, cancer and hypertensive diseases ${ }^{3}$ causing deaths related to ischemic heart diseases and cerebrovascular diseases as major underlying causes of death, when Chagas' disease is presented as an associated cause.

Our data also call attention to cerebrovascular disease, especially ischemic stroke, which is an event often overlooked and not recognized as a complication of Chagas' disease $\mathrm{e}^{3,18}$. Studies have shown that the diagnosis of Chagas' disease often occurred only after the occurrence of stroke ${ }^{19}$ and some considered Chagas' disease as a possible independent risk factor for mortality from ischemic stroke, possibly by cardioembolic mechanism ${ }^{17,20,21}$. Several risk factors, such as heart 
failure, mural thrombi, ventricular apical aneurysm, hypertension and cardiac arrhythmias have been shown to be associated with stroke in patients with Chagas' disease ${ }^{19,21}$. In a study based on autopsies performed in a reference hospital in the State of Bahia between 1956 and 2001, cerebral infarction was reported in $17.5 \%$ of autopsies of chagasic patients with heart failure, and complications were associated with death in $52 \%$ of cases $^{16}$.

Rassi Jr et al. ${ }^{22}$ reviewed studies on the causes of deaths and the frequency of sudden death in different population groups and found that sudden death, cardiac insufficiency and cerebral thromboembolism were the principal causes of death in Chagas' disease. The highest and lowest frequency of a particular case depended on the characteristics of the study population, with predominance of sudden death in those studies that included outpatients, and heart failure in studies with patients hospitalized for cardiac decompensation.

In a study from the State of São Paulo, sudden death (including in arrhythmic disorders /conduction disorder) was rarely mentioned on death certificates, in only $12.8 \%$ of death ${ }^{3}$. The high frequency of heart failure in deaths related to Chagas' disease suggests poor prognosis for patients with this condition, which seems to be associated with increased risk of death, as compared to patients with heart failure due to other etiologies ${ }^{23}$.

The association between arterial hypertension and Chagas' disease in the development of severe cardiac involvement is still a matter of debate in the literature ${ }^{24,25}$. In this study, the increase of hypertensive diseases associated with diabetes mellitus can be attributed to increasing mortality at more advanced ages ${ }^{3}$. In fact, the prevalence of cardiovascular causes observed in the study is partially related to the coexistence of chronic Chagas' disease with the aging process of the population ${ }^{9}$, since cardiovascular diseases are the leading causes of morbidity and mortality among the elderly ${ }^{26}$. In this study, most deaths from Chagas' disease concerned the elderly and patients with chronic cardiac form of the disease. In addition to the functional changes associated with aging of the cardiovascular system, elderly patients were also subject to damage associated with Chagas' heart disease and other cardiovascular diseases such as arterial hypertension and ischemic heart disease. Consequently, they were more vulnerable to clinical decompensation or development of lesions in organs such as brain, kidneys or the heart itself, which culminated in death?

In fact, the predominance of cardiovascular causes observed in the study is linked to coexistence of chronic Chagas' disease ${ }^{9}$ with the aging process of the population, since cardiovascular diseases are the leading causes of morbidity and mortality among the elderly ${ }^{26}$. In addition, the frequent association of chronic disease causes significant demand for health services and medications that predispose to numerous risks, whereas the association between Chagas' disease and other chronic diseases may increase mortality and worsen the quality of life of those who find themselves in this unfavorable condition ${ }^{26}$.

A current challenge is to provide assistance, taking into account the harmful effects of a combination of Chagas' disease and other chronic degenerative diseases ${ }^{9,26}$. The elderly chagasic patients should receive priority attention of health services and social assistance, deserving attention of public managers and health professionals, in order to minimize morbidity and mortality by Chagas' disease.
In addition to cardiovascular disease, there are relevant associations with respiratory diseases, particularly chronic obstructive pulmonary disease (COPD) and pulmonary embolism, digestive diseases and neoplasms. Infectious diseases, particularly sepsis and pneumonia (although this is classified in the diseases of the respiratory system) also play a role. Intestinal infectious diseases, tuberculosis, mainly by coinfection with human immunodeficiency virus (HIV), responsible for high mortality among untreated patients may aggravate these conditions ${ }^{27}$. Knowledge on the associations of causes of death as described in our study may assist in the prevention of joint action of these diseases, in the determination of the deaths for Chagas' disease.

Interpretation of results should consider limitations of the study, such as problems arising from disease notification and data entry ${ }^{28}$. Secondary data often show inconsistencies in the quantity and quality of their information ${ }^{3}$. Deaths may be under-reported, despite the progress made during the observation period in terms of SIM coverage and quality of information on causes of deaths. The coverage (ratio of deaths reported/estimated) also presents variations between regions in the country, mainly in the North and Northeast regions ${ }^{3}$.

Similar to underreporting of deaths, the occurrence of deaths from ill-defined causes is also uneven between regions, with worse indicators outside the state capitals, among children $<1$ years of age, in the poorest population strata, and in rural areas. Deaths due to illdefined causes, rather than identifying the quality of information in the death certificate, probably point to deficiencies in access to health services and quality of attention.

The results of this study show internal consistency and coherence with existing knowledge about Chagas' disease, as well as being highly representative, since it included all death certificates during the period 1999 to 2007 in Brazil, a country of continental dimensions.

We conclude that cardiovascular diseases, particularly heart diseases and cerebrovascular diseases, were the most important associated causes of death in those with Chagas' disease as cause of death. The information from all causes of death recorded on death certificates allows partial reconstruction of the natural history of Chagas' disease and some suggests preventive measures and adequate and specific therapeutic. Knowledge of the full range of causes of deaths related to the disease opens new perspectives for the prevention of deaths and help to guide appropriate care and specific measures.

\section{CONFLICT OF INTEREST}

The authors declare that there is no conflict of interest.

\section{ABSTRACT IN PORTUGUESE}

\section{Causas múltiplas de morte relacionadas à doença de Chagas no Brasil, 1999 a 2007}

Introdução: A doença de Chagas é um importante problema de saúde pública no Brasil e necessita de informações amplas e confiáveis que subsidiem suas ações de prevenção e controle. Este estudo descreve as causas de morte que mais frequentemente se associaram aos óbitos relacionados à doença de Chagas como causa básica e associada de morte. Métodos: Dados de mortalidade foram obtidos do Sistema de Informação sobre Mortalidade do Ministério da Saúde 
(aproximadamente 9 milhões de óbitos). Foram analisados todos os óbitos ocorridos no Brasil entre 1999 e 2007, nos quais a doença de Chagas foi mencionada na declaração de óbito como causa básica ou associada (causas múltiplas de morte). Resultados: Ocorreram 53.930 óbitos relacionados à doença de Chagas, 44.543 (82,6\%) como causa básica e 9,387 (17,4\%) como causa associada. As principais doenças e condições associadas ao óbito por doença de Chagas como causa básica foram as complicações diretas do envolvimento cardíaco, como os transtornos de condução/arritmias (41,4\%) e a insuficiência cardíaca $(37,7 \%)$. As doenças cerebrovasculares $(13,2 \%)$, doenças isquêmicas do coração $(13,2 \%)$ e as doenças hipertensivas $(9,3 \%)$ foram as principais causas básicas nos óbitos em que a doença de Chagas foi identificada como causa associada. Conclusões: As doenças cardiovasculares foram as que mais frequentemente se associaram aos óbitos relacionados à doença de Chagas. As informações relativas às causas múltiplas de morte registradas na declaração de óbito permitem recompor a história natural da doença de Chagas e indicam medidas preventivas e terapêuticas mais adequadas e específicas.

Palavras-chaves: Doença de Chagas. Mortalidade. Causa básica de morte. Causas múltiplas de morte. Epidemiologia. Brasil.

\section{REFERENCES}

1. Word Health Organization. International Statistical Classification of Diseases and Related Health Problems (ICD): 10th Revision. Version 2007: Word Health Organization; 2007. [Cited 2010 October 15]. Available from: http://apps.who. int/classifications/icd10/browse/2010/en.

2. Santo AH, Pinheiro CE. Tabulador de causas múltiplas de morte. Rev Bras Epidemiol 1999; 2:90-97.

3. Santo $\mathrm{AH}$. Tendência da mortalidade relacionada à doença de Chagas, Estado de São Paulo, Brasil, 1985 a 2006: estudo usando causas múltiplas de morte. Rev Panam Salud Publica 2009; 26:299-309.

4. Silveira AC. Os novos desafios e perspectivas futuras do controle. Rev Soc Bras Med Trop 2011; 44:122-124.

5. Ramos Jr AN, Carvalho DM. Doença de Chagas: passado, presente e futuro. Cad Saude Colet 2009;787-794.

6. Word Health Organization. Control of Chagas disease (Technical Report Series 905). Geneva: Word Health Organization; 2002.

7. Dias JCP. Notas sobre o Trypanosoma cruzi e suas características bio-ecológicas, como agente de enfermidades transmitidas por alimentos. Rev Soc Bras Med Trop 2006; 39:370-375.

8. World Health Organization. Working to overcome the global impact of neglected tropical diseases: First WHO report on neglected tropical diseases. Geneva: Word Health Organization; 2010.

9. Guariento ME, Carrijo CM, Almeida EA, Magna LA. Perfil clínico de idosos portadores de doença de Chagas atendidos em serviço de referência. Rev Bras Clin Med 2011; 9:20-24.
10. Martins-Melo FR, Alencar CH, Ramos Jr AN, Heukelbach J Epidemiology of Mortality Related to Chagas' Disease in Brazil, 1999-2007. PLoS Negl Trop Dis 2012; 6:1508.

11. Laurenti RA. Análise da mortalidade por causa básica e por causas múltiplas. Rev Saude Publica 1974; 8:421-435.

12. Ministério da Saúde. Departamento de Informática do Sistema Único de Saúde [Internet]. Brasília: Ministério da Saúde; 2010. [Cited 2010 October 15]. Available from: http://tabnet.datasus.gov.br/cgi/sim/dados/cid10_indice.htm.

13. Ministério da Saúde. Manual de procedimentos do sistema de informações sobre mortalidade. Brasília: Ministério da Saúde; 2001.

14. Ishitani LH, França E. Uso das causas múltiplas de morte em Saúde Pública. Informe Epidemiológico do SUS 2001; 10:163-175.

15. Wanderley DMV, Litvoc J. Doença de Chagas como causa básica de óbito na região sudeste do Brasil: presença de causas contributárias. Rev Saude Publica 1994; 28:69-75.

16. Aras R, Matta JAM, Mota G, Gomes I, Melo A. Cerebral Infarction in Autopsies of Chagasic Patients with Heart Failure. Arq Bras Cardiol 2003; 81: 414-416.

17. Paixão LC, Ribeiro AL, Valacio RA, Teixeira AL. Chagas disease: independent risk factor for stroke. Stroke 2009; 40:3691-3694.

18. Carod-Artal FJ. Stroke: a neglected complication of American trypanosomiasis (Chagas' disease). Trans R Soc Trop Med Hyg 2007; 101:1075-1080.

19. Carod-Artal FJ, Ribeiro LS, Vargas AP. Awareness of stroke risk in chagasic stroke patients. J Neurol Sci 2007; 263:35-39.

20. Lima-Costa MF, Matos DL, Ribeiro ALP. Chagas Disease Predicts 10-Year Stroke Mortality in Community-Dwelling Elderly The Bambuí Cohort Study of Aging. Stroke 2010; 41:2477-2482.

21. Carod-Artal FJ, Vargas AP, Horan RA, Nunes LGN. Chagasic cardiomyopathyis independently associated with ischemic stroke in Chagas disease. Stroke 2005; 36:965-970.

22. Rassi Júnior A, Rassi A, Rassi SG. Predictors of Mortality in Chronic Chagas Disease: A Systematic Review of. Circulation 2007; 115:1101-1108.

23. Freitas HF, Chizzola PR, Paes AT, Lima AC, Mansur AJ. Risk stratification in a Brazilian hospital-based cohort of 1220 outpatients with heart failure: role of Chagas' heart disease. Int J Cardiol 2005; 102:239-247.

24. Guariento ME, Orosz JEB, Gontijo JAR. Interação clínica entre moléstia de Chagas e hipertensão arterial primária em um serviço de referência ambulatorial. Arq Bras Cardiol 1998; 70:431-434.

25. Gurgel CB, Almeida EA. Frequency of hypertension in patients with chronic Chagas disease and its consequences on the heart: a clinical and pathological study. Arq Bras Cardiol 2007; 89:174-182.

26. Alves RMA, Thomaz RP, Almeida EA, Silva J, Wanderley JS, Guariento ME. Chagas' disease and ageing: the coexistence of other chronic diseases with Chagas' disease in elderly patients. Rev Soc Bras Med Trop 2009; 42:622-628.

27. Ministério da Saúde. Recomendações para diagnóstico, tratamento e acompanhamento da co-infeç̧ão: Trypanosoma cruzi/vírus da imunodeficiência humana (HIV). Brasília: Secretaria de Vigilância em Saúde; 2007.

28. Drumond JAG, Marcopito LF. Migração interna e a distribuição da mortalidade por doença de Chagas, Brasil, 1981/1998. Cad Saude Publica 2006; 22:2131-2140. 